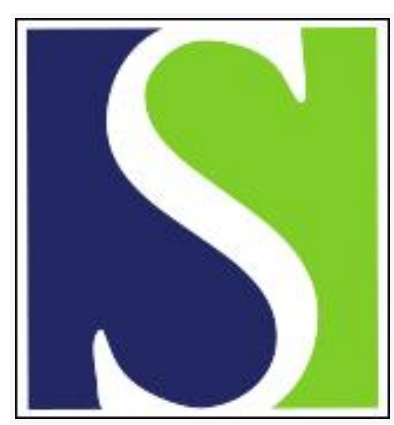

Scand J Work Environ Health 1984;10(6):347-352

https://doi.org/10.5271/sjweh.2308

Issue date: Dec 1984

\title{
Occupational mortality.
}

by Harrington JM

This article in PubMed: www.ncbi.nlm.nih.gov/pubmed/6535238

\section{(c) (1)}




\title{
Occupational mortality
}

\author{
by $\mathrm{J}$ Malcolm Harrington, BSc, MSc, MD, FRCP, FFom ${ }^{1}$
}

\begin{abstract}
HARRINGTON JM. Occupational mortality. Scand J Work Environ Health 10 (1984) 347-352. Mortality statistics have been formally collected in the United Kingdom since the time of John Graunt in 1692. The advent of birth and death registration in 1839 established a reliable system of mortality rate calculations. Occupation was added to the sixth decennial census in 1851, and supplementary occupational mortality reports have been published since that date. The usefulness of these decennial supplements as hypothesis-generating exercises is reviewed. Particular emphasis is placed on the validity of the standardized mortality ratio as an index of comparative mortality. Flaws in the collection and recording of causes of death and occupational status at death and during life are noted, and the ways in which standard reporting of these events could be improved are outlined.
\end{abstract}

Key terms: cancer, occupational epidemiology methods, vital statistics.

Concern about the possible effects of occupation on mortality patterns predates any accurate assessment of the links between work and health. Occupation was infrequently and irregularly noted in parish mortality records, and compulsory notification of occupation did not apply in England and Wales until this piece of information was required for the 1851 census.

Vital registration - that is, the noting of births, deaths and, possibly, marriages - came much earlier. Indeed, it is likely that Egypt at the time of Rameses II (about $1250 \mathrm{BC}$ ) had some form of population registration (19). Most authorities on vital statistics cite John Graunt (1620-1674) and William Petty (1623-1674) as the pioneers of the use of systematic records. They made extensive use of the Bills of Mortality for England and Wales that had been kept to some degree or other - in parishes throughout England and Wales since 1532. By 1625 , two categories of death "plague" and "others," had been established. The accuracy of the early bills was dubious. They were completed by the old women of the parish who were often alcoholic, illiterate, and venal. Betting on the numbers published was a common sport.

Graunt and Petty, nevertheless, advanced vital statistics by their intelligent use of the data at their disposal. They commented on disease patterns. Petty drafted the first life table (26), was clearly aware of the concept of case-referent studies, and made many

\footnotetext{
1 Institute of Occupational Health, University of Birming-
} ham, Birmingham, United Kingdom.

Reprint requests to: Prof JM Harrington, Institute of Occupational Health, University of Birmingham, PO Box 363, Birmingham B15 2TT, United Kingdom. astute observations. Two examples will suffice here (26):

The number of people that are of every yeare old from one to 100 and the number of them that dye at every such yeare's age, do show to how many yeare's value the life of any persons of any age is equivalent and consequently makes a par between the value of estates for life and for yeares.

Whether they (viz. fellows and licentiates of the College of Physicians) take as much medicine and remedies as the like number of any other society .... whether of 1000 patients to the best physicians aged of any decade, there do not dye as many as out of the inhabitants of places where there dwell no physicians.

However, the first true medical statistician was probably William Farr. Born in 1808, this self-taught mathematician was the first to comment on the effects of occupation on mortality when this item was added to the census data in 1851 (4). Thereafter, decennial supplements were published by him and his successors at the General Registry Office [now the Office of Population Censuses and Surveys (OPCS)] through to the present day, the only exception being the year 1941. Farr introduced age standardization and made fruitful use of the registration data as numerator and the census data as denominator. William Ogle (25), commenting on the Decennial Supplement for 1881 , noted a high comparative mortality figure for physicians and publicans. The relatively low figure for fishermen prompted this astute comment (25):

The uncertainty as to the fishermen who die arises from the possibility that some few of those who are drowned and whose bodies are not recovered, may escape registration. 
It took nearly another century for this fact to be rediscovered when Schilling noted that the published mortality statistics of deep-sea trawlermen was grossly underestimated due to the absence of landregistrable deaths for those mariners lost at sea. Their deaths at sea were registered elsewhere (30).

Indeed, the early statisticians at the General Registry Office, such as Ogle and his successor, John Tatham, were aware of the limitations of the calculations based on unlinked data such as registrations and censuses, but they attempted to work within these limitations. Their success was much praised by some commentators (18), less fulsomely by others (2). While some occupational hazards, such as accidents, could be readily linked to mortality, others, such as respiratory diseases or cancer, were less apparent (6). When Stevenson, in his turn, analyzed deaths in 1921-1923, he noted that indirect (way-of-life) factors might also be of importance (33). He noted that data on women might be a way of differentiating "way-of-life" factors from occupational factors when their mortality was compared with that of their husbands (33).

Again, however, one can find earlier examples of how such a mathematical manipulation had already borne fruit, in that Edward Greenhow (1814-1888), using unpublished data of the General Registry Office for lead mining towns in the mid-19th century, showed a differential mortality rate for pulmonary disease, not only between men and their wives, but also between lead mining towns and rural areas (table 1) (31).

The influence of social class as a factor in mortality was noted first by Stevenson, and our current socioeconomic classifications arise directly from his pioneering work. This concept of way of life and occupation as complementary, but possibly confound-

Table 1. Average annual death rates per 1000 from pulmonary disease in men and women over 20 years of age in Alston and Reith (mining towns) and Haltwistle (rural), 1848-1854.

\begin{tabular}{lrc}
\hline Area & Men & Women \\
\hline Alston & 14.4 & 7.8 \\
Reith & 13.0 & 7.2 \\
Haltwistle & 3.7 & 5.8 \\
\hline
\end{tabular}

ing, factors in occupational mortality statistics has now reached a considerable degree of differentiation - particularly noteworthy in the 1971 Decennial Supplement (24).

One further broad category of mortality data analysis worth mentioning at this stage is the influence of geography. While such patterns are clearly visible in the 1971 Decennial Supplement, mapping techniques since then have provided a rich source for "hypothesis generation exercises," both in the United States (20) and, more recently, in the United Kingdom (10). In the United States, a series of papers was spawned by these maps, whereby censuses of manufacturing were linked to area mortality to see if industry concentrations could be linked to geographic patterns of cause-specific mortality (16). There has not yet been time for the more recent British maps to stimulate a similar spate of speculative papers, but even a brief perusal can reveal some unusual, if already described, patterns, such as the cluster of female mesothelioma deaths among Nottingham gas mask assemblers, while the equivalent male maps show concentrations of cases in the shipyards and textile centers (35).

\section{Limitations of occupational mortality studies}

\section{Standardized mortality indices}

Over the last 80 years the standardized mortality ratio (SMR) and the proportionate mortality ratio (PMR) have been the dominant indices in use. The direct standardization technique of the comparative mortality figure (CMF) slowly gave way to the indirect method of the standardized mortality ratio during the period 1911-1931. By the 1931 supplement, the standardized mortality ratio was in exclusive use. The comparative and standardized mortality ratios are usually equal, but, if excess mortality is concentrated at ages at which the occupation has relatively greater numbers than the standard population, then the standardized mortality ratio gives more emphasis to this excess than does the comparative mortality ratio. The latter is more affected by random error in these age-specific death rates - par-

Table 2. Deaths due to cancer in a sheep-dip production site, the factory workers being compared with three other occupational groups living in the same area [adapted from Hill \& Faning (15)].

\begin{tabular}{lccccc}
\hline \multirow{2}{*}{ Tumor site } & \multicolumn{2}{c}{ Sheep-dip workers } & & \multicolumn{2}{c}{ Three other occupational groups } \\
\cline { 2 - 5 } \cline { 5 - 6 } & $\begin{array}{c}\text { Number of } \\
\text { deaths }\end{array}$ & $\begin{array}{c}\text { Percentage } \\
\text { of deaths }\end{array}$ & & $\begin{array}{c}\text { Number of } \\
\text { deaths }\end{array}$ & $\begin{array}{c}\text { Percentage } \\
\text { of deaths }\end{array}$ \\
\hline Buccal cavity or pharynx & 2 & 9.1 & 10 & 6.4 \\
Digestive organs or peritoneum & 5 & 22.7 & 91 & 58.0 \\
Respiratory organs & 7 & 91.8 & 25 & 15.9 \\
Genitourinary organs & 2 & 13.6 & 2 & 1.3 \\
Skin & 3 & 13.6 & 16 & 10.2 \\
Other sites or unspecified & 22 & 99.9 & 157 & 100.1 \\
\hline All sites & & & & 2 \\
\hline
\end{tabular}


ticularly if the occupational populations are small (14).

The proportionate mortality ratio, for many years vilified as a dangerously inaccurate predictor of mortality patterns, has seen some resurgence of interest lately, due in large measure to the original reason for it being invoked, namely, the absence of denominator data on the occupational population of interest. Despite the obloquy heaped upon it, one of the classic occupational mortality studies of the past, by Hill \& Faning, which provided the first reliable information of the human carcinogenicity of arsenic, was a proportional mortality study (15). The data provided by this study clearly shows the link between skin and respiratory cancer and sheep-dip work (table 2). The flaw in the technique, of course, lies in the fact that, if some diseases are in excess, then others must be in deficit. Perhaps the data from this study shows a protective effect of arsenic on the development of gastrointestinal neoplasia!

However, if literature citations were based on the statistical tools involved, the standardized mortality ratio would be by far the most cited index. In essence, it is a summary index of mortality expressed as the observed mortality experience of the occupational study population relative to the mortality that would otherwise be expected in a standard population. Traditionally the standard population has usually been the general population of the country in which the occupational population of interest resides. Occasionally this general population experience is refined by area-specific or socioeconomicspecific weightings, but, most commonly, the whole population of the equivalent age range is used as the comparative group. As this group is large in comparison with the occupational group, some statistical strength is obtained, but, as Gaffey pointed out (9), the limitations are considerable. He noted that there is essentially no relationship between the standardized mortality ratio of a population and the life expectancy of that population. Secondly, the size of the standardized mortality ratio is not, in general, equal to the size of the relative risk (the discrepancy depending upon the age of the study population). Thirdly, at older ages, the standardized mortality ratio is subject to limitations on its possible values, more or less independently of any hazard to which the study population may be exposed.

McMichael noted that standardized mortality ratios calculated for two or more study populations, although using the same standard population, cannot themselves be directly compared with each other (21). More importantly, he noted that the difference in mortality experience between an occupational group with no particularly hazardous conditions and the general population usually results in a mortality risk for the occupational group of $60-90 \%$ of that of the general population. This deficit McMichael called the "healthy worker effect." He further defined this entity by noting that the healthy worker effect diminishes with age and varies with the cause of death at any age. That is, it is more noticeable for active workers and for chronic disease with a progressive clinical course (cardiorespiratory disorders, for example). The effect is the least noticeable for cancers (22).

The healthy worker effect has been consistently cited since then in numerous studies, of which Fox \& Collier's is the most often quoted (7), but in recent years this phenomenon has been described for what it really is, a methodological flaw in study design. As Wang \& Miettinen (34) have noted:

\section{Each occupational setting has its characteristic re- quirements and incentives for job entry... and exit..., and these, when different for the index population and the "general population" and also when related to mortality, produce the healthy worker effect.... The healthy worker effect is a ref- lection of the incomparability of compared popula- tions only - a matter of confounding - and it is not a result of incomparability of the effects or in- formation [p 157].}

Standardized mortality ratios are not without value, however, but some refinement of their use is called for. At the very least, area or socioeconomic weighting is needed for the standard population. Preferably comparative employed populations without the occupational risk factors under study would serve better, and, in addition, a weighting procedure for the variable age-specific effects of the standardized mortality ratio can be computed (27). It is even possible to derive an algebraic relationship between the standardized and proportional mortality ratios, the validity of the proportional mortality ratio as a measure of comparative mortality thereby depending on the homogeneity of the age-specific overall standardized mortality ratios and the value of the average overall standardized mortality ratio (36).

\section{Cause of death}

Thus far assumptions have been made that the flaws in occupational mortality analyses reside in the computations resulting from the linkage of death registrations with population-based denominators. More fundamentally, flaws exist in the classification of death itself. Even in Western countries which pride themselves on their near total death certification, the present system of certification and coding leaves plenty of scope for inaccuracies, omissions, or even frank deception.

The original objectives of the system of death certification - at least in the United Kingdom - was "first to facilitate legal proof of death, and secondly, to produce more accurate mortality statistics [p 206]" (28). Such a system deters crime and provides useful pointers to etiologic agents, but errors are possible. Many patients die at home, often of a chronic illness which may or may not have been accurately diagnosed in life, but in which the immediate cause of 
death is a complication. Even hospital deaths with their higher autopsy rates show notable discrepancies between postmortem findings and original death certification details. The current trend towards fewer autopsies, plus the ethnic or religious differences in autopsy rates, can have a considerable bearing on the accuracy of death certificates.

Further errors arise through the inexperience of the certificating doctor, failure to incorporate additional postmortem information, and, in the past, the misclassification of diseases in the International Coding System. Urgency to achieve burial may result in immediate causes of death being provided without the crucial underlying causes being added, and thus the underlying causes are unavailable for subsequent statistical analysis.

Nevertheless, when these certificates are used for occupational mortality studies, where causes of death are relatively broad, for decedents of middle to old age but not the very elderly, the accuracy is sufficiently good to provide a great deal of useful information (1). Indeed a recent review of ischemic heart disease deaths in Australia suggested a diagnostic accuracy in excess of $90 \%$, though the accuracy for acute myocardial infarction and other subcategories

Table 3. Pneumoconiosis deaths in end occupations in England and Wales (1970-1972) between the ages of 15 and 74 years (24).

\begin{tabular}{lc}
\hline Occupation & Number of deaths \\
\hline Warehouse workers and storekeepers & 28 \\
Stationary engine drivers & 23 \\
Clerks & 11 \\
Guards and related workers & 9 \\
Caretakers & 6 \\
Salesmen & 4 \\
\hline
\end{tabular}

of ischemic heart disease was less reliable (3). Comparable data from the United States concur with these findings, but go on to criticize the current diagnostic criteria of the World Health Organization (11). Further inaccuracies can be noted when international comparisons are made (29) - one of the reasons for instituting an internationally agreed set of diagnostic criteria. Fewer broad diagnostic errors now occur, though these were sufficiently serious in the 1930s to mask an excess of respiratory disease in Lancashire cotton workers, for whom the deaths were grouped with cardiovascular and/or renal disease. A reanalysis of these certificates by Schilling \& Goodman led to the modern resurgence of interest in byssinosis (32). Until their discovery of the hidden respiratory deaths, byssinosis was considered by many to be a disease of purely historical interest.

\section{Categorization of occupation}

Despite improvements in diagnostic accuracy and classification, a major flaw remains, namely, the section on the certificate relating to occupation. Many countries, including the United Kingdom, still only note the last full-time occupation. This procedure can lead to obvious errors in analysis, such as the pneumoconiosis deaths noted in occupations with little obvious dust exposures.

Occupations such as those listed in table 3 are clearly jobs taken by miners after retirement (possibly on health grounds) from their life-long occupation. The Royal College's report suggests that, in the future, the type of industry should be recorded, that married women should be recorded by their occupation not just that of their husband, and that "consideration should be given" to the recording of main

Table 4. Distribution of occupation of occupied men dying in 1955 (13).

\begin{tabular}{|c|c|c|c|c|}
\hline \multirow[b]{2}{*}{ Occupational group } & \multicolumn{2}{|c|}{ Number reported } & \multirow{2}{*}{$\begin{array}{l}\text { Percentage } \\
\text { difference }^{a}\end{array}$} & \multirow{2}{*}{$\begin{array}{l}\text { Percentage } \\
\text { difference } \\
\text { "retired" } \\
\text { included }\end{array}$} \\
\hline & $\begin{array}{l}\text { "Official" } \\
\text { (a) }\end{array}$ & $\begin{array}{l}\text { Independent } \\
\text { (b) }\end{array}$ & & \\
\hline $\begin{array}{l}\text { Supervisors } \\
\text { Faceworkers } \\
\text { Other underground workers } \\
\text { Surface workers }\end{array}$ & $\begin{array}{r}203 \\
646 \\
1100 \\
390\end{array}$ & $\begin{array}{r}196 \\
466 \\
1140 \\
484\end{array}$ & $\begin{array}{r}+3.4 \\
+27.9 \\
-3.6 \\
-24.1\end{array}$ & $\begin{array}{l}+14.8 \\
+43.1 \\
+2.9 \\
-23.4\end{array}$ \\
\hline
\end{tabular}

a $(a-b) / a$.

Table 5. Revision of cause of death in light of autopsy and/or histology reports (23).

\begin{tabular}{lcccr}
\hline Disease & $\begin{array}{c}\text { Number } \\
\text { certified }\end{array}$ & $\begin{array}{c}\text { Number } \\
\text { added }\end{array}$ & $\begin{array}{c}\text { Number } \\
\text { removed }\end{array}$ & $\begin{array}{r}\text { Revised } \\
\text { number }\end{array}$ \\
\hline 1. Cancer of lung + asbestosis & 29 & 3 (from disease category 2) & 5 & 27 \\
2. Asbestosis without lung tumor & 15 & 0 & 3 & 12 \\
3. Gastrointestinal tumors & 14 & 0 & 4 & 7 \\
4. Other tumors & 10 & 0 & 0 & 6 \\
5. Mesothelioma & 1 & 5 (from disease category 1) & 0 \\
$\quad$ Pleural & 3 & 7 (from disease category 3) & 0 & 13 \\
$\quad$ Peritoneal & 12 & 3 (from disease category 4) & 0 & 12 \\
6. Other diseases & 12 & 0 & & \\
\hline
\end{tabular}


occupation if different from last occupation. This attempt to avoid some obvious flaws is reiterated in the recent House of Lords Select Committee report on occupational health services (17).

Another inaccuracy of occupational status on death certificates is the predilection of relatives to "promote" the deceased. Heasman (13) in a survey of coal miners' occupation at death compared the "official" occupation with that of the employer's records. Relatives were seen to promote their deceased kin to jobs either of a higher grade or closer to the more prestigious coalface working than the lower rank jobs or "surface" work. Such inaccuracies can be considerable (table 4).

Some studies have attempted to compare the official certificates with hospital and/or autopsy records of the cases. Newhouse \& Wagner (23), in a study of asbestos workers, found that there was no gross underestimation of asbestosis or carcinoma of the bronchus, but additional lung tumors were found from autopsy or histology reports. More significantly, mesothelioma was underestimated in official certificates (table 5).

\section{Future considerations for improving the data base}

It is clear, from the preceding discussion, that, despite the wealth of occupational mortality data available in many countries, in some cases spanning over a century, the flaws in diagnostic accuracy and occupational classifications and the inappropriate comparison of census data with registration data do present significant problems for the valid interpretation of such data. As the grosser occupational mortality characteristics are delineated, the need to refine the basic information to have value in discovering more subtle occupational factors becomes greater. Various techniques are being developed which should help in this process of "quality control."

In the United Kingdom, in future years, the Decennial Supplement will be supported by a new study, the OPCS Longitudinal Study. From 1971 on, events such as births, cancer registrations, widowhoods, and deaths in a $1 \%$ sample of the population are being related to the census characteristics of the sample (5). Information contained in the 1981 and subsequent censuses will also be added to this study, and thereby a powerful research instrument should be provided. One percent of the population will comprise relatively few deaths in any one year, but over 5 to 10 years such an accumulation will provide an important background to subsequent decennial supplements. The power of this device will be to avoid the inaccuracies of currently unlinked data as, in the future, census data on occupation will be linked with mortality instead of relying on "last" occupation details provided by the decedent's relatives.
Other linkage methods are also under study. Census-based occupational mortality studies have already been undertaken for a number of industries for which other methods would be impossible. A recent study of the fertilizer industry by Fraser and her colleagues was census-based (8), and the author is currently analyzing the mortality experience of a population who, in the $1961-1971$ census, stated that their occupation was in the pharmaceutical industry.

The ability to link cancer registers, factory registers, and other sources of mortality and morbidity is reviewed elsewhere in this journal (12); the review covers the use of job exposure matrices, integrated exposure assessments, and serially additive exposure dosages.

\section{Conclusions}

The development of occupational mortality statistics over the past century has provided epidemiologists with a wealth of data from which a number of important etiologic studies of mortality factors associated with occupation have been derived. Nevertheless, the unlinked data bases are proving inadequate to cope with the increasing sophistication required to delineate the more subtle influences of occupation on mortality. Improvements in the accuracy of the raw data are being supplemented by the development of linked record systems which should assist etiologic searches. Nevertheless, even these developments will take years to bear fruit, and, in the meantime, many more deaths are, by definition, required to "fuel" the new analytical procedures. Thus morbidity studies of more accurate capability are required as well. Such studies form the subject of another report (12).

\section{References}

1. Adelstein AM. Certifying cause of death. Health Trends 9 (1977) 78-81.

2. Alderson MR. Some sources of error in British occupational mortality data. Br J Ind Med 29 (1972) 245-254.

3. Dobson AJ, Gibberd RW, Leeder SR: Death certification and coding for ischaemic heart disease in Australia. Am J Epidemiol 117 (1983) 397-405.

4. Farr W. First annual report of the Registrar General. Her Majesty's Stationery Office, London 1851.

5. Fox AJ. The role of OPCS in occupational epidemiology: Some examples. Ann Occup Hyg 21 (1979) 393-403.

6. Fox AJ. Linkage methods in occupational mortality. In: McDonald JC, ed. Recent advances in occupational health. Churchill Livingstone, Edinburgh 1981, pp 107-117.

7. Fox AJ, Collier PF. Low mortality rates in industrial cohort studies due to selection for work and survival in the industry. Br J Prev Soc Med 30 (1976) 225-230.

8. Fraser P, Chilvers C, Goldblatt P. Census based mortality study of fertiliser manufacturers. $\mathrm{Br} \mathrm{J}$ Ind Med 39 (1982) 323-329.

9. Gaffey WR. A critique of the standardised mortality 
ratio. J Occup Med 18 (1976) 157-160.

10. Gardner MJ, Winter PD, Taylor CP, Acheson ED. Atlas of cancer mortality in England and Wales 1968-1978. John Wiley, Chichester 1983.

11. Gillum RF. On death certification and coding for ischaemic heart disease. Am J Epidemiol 119 (1984) 650.

12. Harrington JM. Epidemiologic study of work-related diseases: Methodological problems of register-based studies. Scand J Work Environ Health 10 (1984) $353-359$.

13. Heasman MA, Liddell FDK, Reid DD. The accuracy of occupational vital statistics. Br J Ind Med 15 (1958) $141-146$.

14. Hill AB. Principles of medical statistics. Eighth edition. Lancet, London 1977.

15. Hill AB, Faning EL. Studies in the incidence of cancer in a factory handling inorganic compounds of arsenic. Br J Ind Med 15 (1948) 1-6.

16. Hoover R, Fraumeni JF. Cancer mortality in US counties. Environ Res 9 (1975) 196-207.

17. House of Lords Select Committee on Science and Technology. Occupational health and hygiene services. Volume 1. Her Majesty's Stationery Office, London 1984.

18. Logan WPL. Cancer mortality by occupation and social class 1851-1971. International Ágency for Research on Cancer, Lyon 1982. (IARC scientific publications no 36). \& Her Majesty's Stationery Office, London 1982. (Studies on medical and population subjects no 44).

19. Logan WPL, Lambert PJ. Vital statistics. In: Hobson W, ed. Theory and practice of public health. Fifth edition. Oxford Unversity Press, Oxford 1979, pp 9-31.

20. Mason TJ, McKay FW, Hoover R, Blot WJ, Fraumeni JF. Atlas of cancer mortality for US counties 19501969. Department of Health, Education \& Welfare, Washington, DC 1975. (DHEW publication no (NIH) 75-780).

21. McMichael AJ. Standardised mortality ratios and the "healthy worker effect": Scratching beneath the surface. J Occup Med 18 (1976) 165-168.

22. Milham S. Mortality experience of the AFL-CIO United Brotherhood of Carpenters and Joiners of America 1969-70. Department of Health Education \& Welfare, Washington, DC 1974. (DHEW publication no
(NIOSH) 74-129).

23. Newhouse ML, Wagner JC. Validation of death certificates in asbestos workers. Br J Ind Med 26 (1969) 302-307.

24. Office of Population, Censuses and Surveys. Decennial supplement of occupational mortality 1970-1972. Her Majesty's Stationery Office, London 1978. (Series DS 1).

25. Ogle W. Letter to the Registrar General. In: Decennial supplement to 45th annual report of the Registrar General. Her Majesty's Stationery Office, London 1885.

26. Petty W. Essays in political arithmetic concerning the growth of the city of London. National and Political Observations, London 1685 \& 1699.

27. Ranstam J. Comparisons of standardized mortality ratios. Scand J Work Environ Health 10 (1984) 63.

28. Royal College of Physicians and Royal College of Pathologists. Joint report: Medical aspects of death certification. J R Coll Physicians London 16 (1982) 205-218.

29. Reid DD, Rose GA. Assessing the comparability of mortality statistics. Br Med J 2 (1964) 1437-1439.

30. Schilling RSF. The hazards of deep sea fishing. Br J Ind Med 28 (1971) 27-35.

31. Schilling RSF. Developments in occupational health. In: Schilling RSF, ed. Occupational health practice. Second edition. Butterworths, London 1981, pp $10-26$.

32. Schilling RSF, Goodman N. Cardiovascular disease in cotton workers: Part I. Br J Ind Med 8 (1951) 77-87.

33. Stevenson THC. The social distribution of mortality from different causes in England and Wales 19101912. Biometrika 15 (1923) 382-400. Cited in: Fox A Adelstein AM. Occupational mortality: Work or way of life. J Epidemiol Community Health 32 (1978) $73-78$.

34. Wang J-D, Miettinen OS. Occupational mortality studies: Principles of validity. Scand $J$ Work Environ Health 8 (1982) 153-158.

35. Wignall BK, Fox AJ. Mortality of female gas mask assemblers. Br J Ind Med 39 (1982) 34-38.

36. Wong $O$, Decoufle $P$. Methodological issues involving the standardised mortality ratio and proportionate mortality ratio in occupational studies. J Occup Med 24 (1982) 299-304. 